\title{
Phosphoric and carboxylic methacrylate esters as bonding agents in self-adhesive resin cements
}

\author{
WENSHU LIU ${ }^{1}$, HONGMEI MENG ${ }^{2}$, ZHIGUANG SUN ${ }^{3}$, RIWEN JIANG ${ }^{4}$, \\ CHANG-AN DONG ${ }^{5}$ and CONGXIAO ZHANG ${ }^{1}$
}

\begin{abstract}
Departments of ${ }^{1}$ Stomatology and ${ }^{2}$ Neurology, The First Hospital of Jilin University; ${ }^{3}$ Department of Stomatology, Jilin Province Hospital; ${ }^{4}$ Department of Stomatology, 461 Outpatient Department, 208 Military Hospital, Changchun, Jilin 130021; ${ }^{5}$ Department of Endodontics, Bai-He Stomatological Hospital, Changchun, Jilin 130041, P.R. China
\end{abstract}

Received October 4, 2016; Accepted November 17, 2017

DOI: $10.3892 /$ etm.2018.5937

\begin{abstract}
The aim of the present study was to investigate the effect of $\mathrm{pH}$ and phosphoric ester structure (phosphonate or phosphate) on the bond strength of different dental restorative materials. The following three self-adhesive resin cements were used in the present study: RelyX ${ }^{\mathrm{TM}}$ Unicem, Maxcem and Multilink Sprint The $\mathrm{pH}$ of each cement was measured using a $\mathrm{pH}$ meter. The cements were used to attach a variety of restorative materials to human dentin and the bond strength was measured by assessing shear strength using a universal testing machine. The $\mathrm{pH}$ values of RelyX Unicem, Maxcem and Multilink Sprint were 3.78, 1.78 and 3.42, respectively. Maxcem, a phosphate-based self-adhesive cement, was demonstrated to form the weakest bonds. No significant difference in bond strength was observed between RelyX Unicem and Multilink Sprint, which are phosphonate-based cements. The results of the present study suggest that the chemical structure of the functional monomer influences the performance of an adhesive material. Furthermore, the $\mathrm{pH}$ of acidic functional monomers containing phosphonate or phosphate groups has an effect on the strength of bonds formed between dentin and restorative materials.
\end{abstract}

\section{Introduction}

Luting agents have been used in dentistry for over a century. According to ISO, these materials are categorized as water-based or polymer-based depending on their principal curing mechanism (1). In the literature, the term resin cement is often used to describe polymer-based luting materials (2).

The use of self-etching, self-adhesive resin cements has increased in recent years (3). These materials combine an adhesive and a cement in a single application, eliminating the

Correspondence to: Professor Congxiao Zhang, Department of Stomatology, The First Hospital of Jilin University, 71 XinMin Street, Changchun, Jilin 130021, P.R. China

E-mail: zhang_congxiao@yahoo.com; zhangcx7400@sina.com

Key words: self-adhesive resin cements, phosphonate, phosphate, shear bond strength need for pre-treatment of the tooth (4). Due to their ease of use, self-adhesive resin cements are commonly employed to adhere restorative materials to teeth (5). A key component of these cements is an acid methacrylate ester consisting of a hydrophilic end group, an alkyl chain spacer 3-11 $\mathrm{CH}_{2}$ groups long and a polymerizable methacrylate group. In order to promote adhesion between the luting agent and the tooth substrate, carboxylic or phosphoric acid-functionalized monomers, such as methacrylate monomers, are utilized to achieve enamel and dentin demineralization (6). The acidic groups bind to calcium in the hydroxyapatite of the demineralized smear layer, creating a bond to the resin network (7). The adhesion mechanism of these materials is not based on hybrid layer or tag formation, as only a partial smear layer with dentin demineralization or infiltration of dentin is generally observed (8).

The concentration of acidic monomers serves a crucial role in the curing process. The concentration must be high enough to guarantee proper demineralization and bonding to dentin and enamel, whilst also being low enough to avoid excessive hydrophilicity in the cured material (9). As reported by Ferracane et al (10), hydrophilicity due to low $\mathrm{pH}$ in the cured material may compromise mechanical stability by promoting excessive water adsorption.

The hydrophilic end group of resin cements is often acidic, consisting of a phosphoric acid derivative such as a phosphonate $\left(\mathrm{H}_{2} \mathrm{PO}_{3}{ }^{+} / \mathrm{HRPO}_{3}{ }^{+}\right)$or phosphate $\left(\mathrm{H}_{2} \mathrm{PO}_{4}^{-} / \mathrm{HRPO}_{4}^{-}\right)$group. These acidic groups simultaneously etch and infiltrate enamel and dentin and are thought to bond chemically to $\mathrm{Ca}^{2+}$ in the hydroxyapatite of the tooth and to superficial oxides on the restorative material $(11,12)$.

In the present study, the $\mathrm{pH}$ of three self-adhesive resin cements was measured and the effect of phosphoric ester type (phosphonate or phosphate) on bond strength was assessed. The null hypothesis was that $\mathrm{pH}$ and acidic behavior of self-adhesive resin cements would have no influence on the long-term mechanical properties of bonds between human dentin and dental materials.

\section{Materials and methods}

Materials. The self-adhesive resin cements used were RelyX Unicem (3M ESPE AG, St. Paul, MN, USA), Maxcem 
(Kerr-Hawe, Orange, CA, USA), and Multilink Sprint (Ivoclar Vivadent, Schaan, Liechtenstein). The materials and their compositions are described in Table I.

Preparation of dentin specimens. The dentin specimens were obtained from 120 caries-free third human third molars within 3 months of extraction between September 2014 and November 2015. All patients provided prior written informed consent and the study protocol was approved by the Ethics Committee at the First Hospital of Jilin University (Changchu, China). The teeth were stored in an aqueous $1 \%$ chloramine $\mathrm{T}$ solution (Thermo Fisher Scientific, Inc., Waltham, MA, USA) at $4^{\circ} \mathrm{C}$ until use. As previously described (13), the teeth were embedded in self-curing acrylic resin (Plexil A6; Escil, Chassieu, France) in a cylindrical mold (30 $\mathrm{mm}$ in diameter and $15 \mathrm{~mm}$ in height). Following polymerization of the resin, the occlusal enamel each tooth was removed perpendicular to the long axis of the tooth using a low-speed diamond disk saw (IsoMet; Buehler, Lake Bluff, IL, USA). Prior to bonding, the specimens were randomly divided into 12 groups of 10 teeth and stored in distilled water at $37^{\circ} \mathrm{C}$.

The restorative materials included $\mathrm{Ni}-\mathrm{Cr}$-based alloy (10\% Cr, 4\% Mo; Goodfellow, Lille, France), micro-filled veneering composite resin (Adoro; Ivoclar-Vivadent, Schaan, Liechtenstein), glass-ceramic (E-Max; Ivoclar-Vivadent), and sintered Yttria-tetragonal zirconia polycrystalline ceramicY-TZP zirconium ceramic; (HTI, Decines, France). The materials were appropriately tooled, molded, cast or sintered to obtain cylindrical samples $5 \times 5 \mathrm{~mm}$. The bonding surfaces of each cylinder were ground using 800-grit SiC paper under running tap water $\mathrm{T} 16^{\circ} \mathrm{C}$ for $1-3$ min depending on the hardness of the materials. The composites and alloy samples were then sandblasted using $50 \mu \mathrm{m} \mathrm{Al}_{2} \mathrm{O}_{3}$ powder under $0.4 \mathrm{MPa}$ pressure for $10 \mathrm{sec}$, while the zirconia and E-Max surfaces were kept in the polished state. The experimental groups and treatments are listed in Table II. Each sample was washed with acetone prior to priming or bonding.

Bonding procedure and measurements. The self-adhesive cements were mixed and directly applied as a thin layer to the substrates and dentin surfaces. The samples were positioned in a fixture to align the cylinders on each dentin surface and subsequently fixed in position with screws tightened to exert a pressure of $\sim 20 \mathrm{~N}$. Excess cement was carefully removed. The luting cements of the composite, glass-ceramic and zirconium groups were light-cured on opposite sides for $20 \mathrm{sec}$ each side. The cement joints of the alloy group were not light-polymerized in order to simulate clinical conditions. Each bonded assembly was maintained under constant pressure for $10 \mathrm{~min}$ in the alignment device in air at room temperature. The specimens were then stored in $100 \%$ relative humidity at $37^{\circ} \mathrm{C}$ for 1 day (Fig 1). Bond strength was measured in shear mode using a universal testing machine (LRX; JJ Lloyd Instruments, Fareham, UK) at a crosshead speed of $0.5 \mathrm{~mm} / \mathrm{min}$. The failure load in $\mathrm{N}$ was divided by the bond area in $\mathrm{mm}$ to obtain the SBS in MPa. The results of the bond strength tests were analyzed using the descriptive and inferential statistics of the Kruskal-Wallis and Games-Howell tests. In order to compare the average bond strength of substrates in various groups of luting cements
Table I. Composition and $\mathrm{pH}$ of resin cements.

\begin{tabular}{llc}
\hline Cement & \multicolumn{1}{c}{ Composition (\%) } & pH \\
\hline RelyX Unicem & $\begin{array}{l}\text { Methacrylated phosphoric } \\
\text { acid esters (15-25) }\end{array}$ & 3.78 \\
& TEGDMA (10-20) & \\
& Fillers (55-75) & \\
GPDM (20-35) & 1.78 \\
& Bis-GMA, TEGDMA and & \\
fillers (67) & 3.42 \\
Multilink Sprint & $\begin{array}{l}\text { Dimethacrylate (24-26) } \\
\text { Methacrylated phosphoric }\end{array}$ & \\
& acid ester (5) & \\
& Fillers (71) & \\
\hline
\end{tabular}

TEGDMA, triethyleneglycoldimethacrylate; GPDM, glycerol dimethacrylate dihydrogen phosphate; Bis-GMA, 2,2-bis[4-(2hydroxy-3-methacryloxypropoxy)phenyl]-propane.

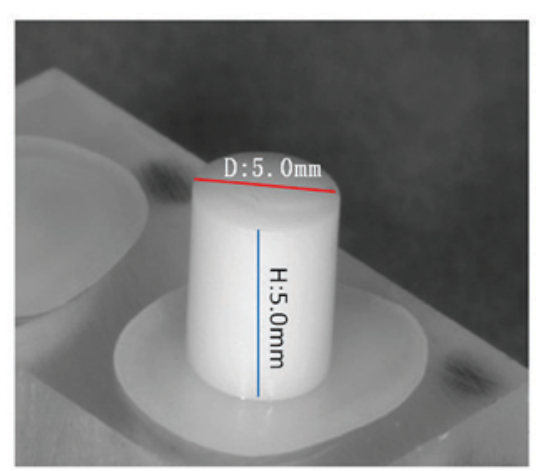

Figure 1. Example of micro-filled veneering composite resin bonded to dentin. Specimen to perform the shear bond strength test: $\mathrm{D}=5.0 \mathrm{~mm}, \mathrm{H}=5.0 \mathrm{~mm}$. D, diameter; $\mathrm{H}$, height.

Kruskal-Wallis analysis was used. The Games-Howell post hoc test was employed to characterize the average bond strengths of the luting cements between substrate and dentin. $\mathrm{P} \leq 0.05$ was considered to indicate a statistically significant difference.

pH measurements. $\mathrm{pH}$ measurements were obtained using a pH meter (PHM MeterLab 210; Hach Company, Loveland, $\mathrm{CO}$, USA). Because the adhesive formulations did not contain water, the contact surface of the electrode was wetted with distilled water containing a neutral $\mathrm{pH}$ buffer. The results of the $\mathrm{pH}$ measurements are located in Table I.

Scanning electron microscopy. Representative samples were sectioned perpendicular to the bonded surface using successively finer diamond abrasives up to 4,000-grit (Isomet; Buehler, Lake Bluff, IL, USA) under water. The samples were coated with gold using an SC 500 (Bio-Rad Laboratories, Inc., Hercules, CA, USA) coater and the restorative/dentin interface was examined using a JSM 6400 scanning electron microscope (Jeol, Tokyo, Japan) at $15-20 \mathrm{kV}$ with a beam intensity of $10^{-11} \mathrm{~A}$ (Figs. 2 and 3 ). 
Table II. Experimental groups and treatment protocols.

\begin{tabular}{rllll}
\hline Group & Substrate & Substrate pretreatment & Resin cement & Curing mode \\
\hline 1 & $\mathrm{Ni}-\mathrm{Cr}$ & $\mathrm{Al}_{2} \mathrm{O}_{3}$ sandblasting & Rely X Unicem & Auto-cured \\
2 & $\mathrm{Ni}-\mathrm{Cr}$ & $\mathrm{Al}_{2} \mathrm{O}_{3}$ sandblasting & Maxcem & Auto-cured \\
3 & $\mathrm{Ni}-\mathrm{Cr}$ & $\mathrm{Al}_{2} \mathrm{O}_{3}$ sandblasting & Multilink Sprint & Auto-cured \\
4 & Composite & $\mathrm{Al}_{2} \mathrm{O}_{3}$ sandblasting & Rely X Unicem & Dual-cured \\
5 & Composite & $\mathrm{Al}_{2} \mathrm{O}_{3}$ sandblasting & Maxcem & Dual-cured \\
6 & Composite & $\mathrm{Al}_{2} \mathrm{O}_{3}$ sandblasting & Multilink Sprint & Dual-cured \\
7 & E-Max & $\# 800 \mathrm{SiC}$ & Rely X Unicem & Dual-cured \\
8 & E-Max & $\# 800 \mathrm{SiC}$ & Maxcem & Dual-cured \\
9 & E-Max & $\# 800 \mathrm{SiC}$ & Rely X Unicem & Dual-cured \\
10 & $\mathrm{ZrO}_{2}$ & $\# 800 \mathrm{SiC}$ & Maxcem & Dual-cured \\
11 & $\mathrm{ZrO}_{2}$ & $\# 800 \mathrm{SiC}$ & Multilink Sprint & Dual-cured \\
12 & $\mathrm{ZrO}_{2}$ & $\# 800 \mathrm{SiC}$ & Dual-cured \\
\hline
\end{tabular}

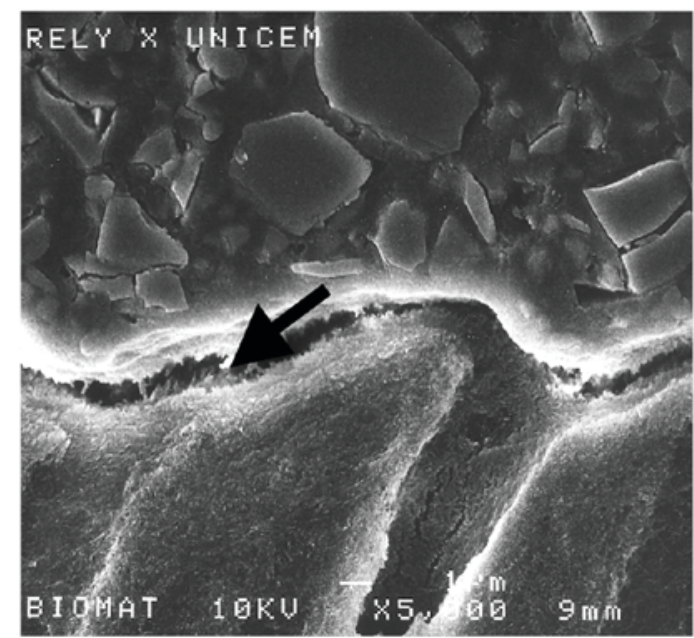

Figure 2. Scanning electron microscopy image of RelyX Unicem bonded to dentin. The arrow indicates the interfacial gaps located in the weak smear layer. Magnification, x5,000.

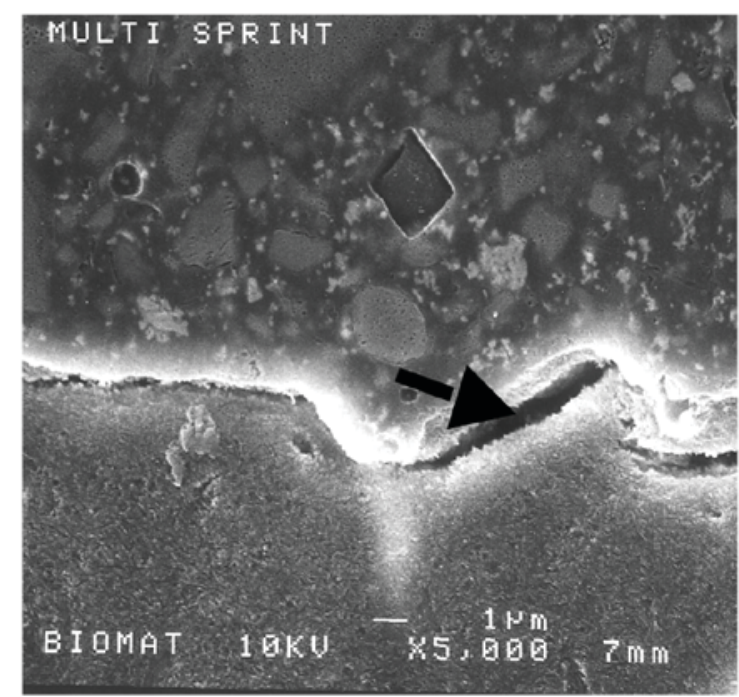

Figure 3. Scanning electron microscopy image of Multilink Sprint bonded to dentin. The arrow indicates the interfacial gaps located in the weak smear layer. Magnification, x5,000.

\section{Results}

Shear bond strength. The bond strength test results are presented in Table III and Fig. 4. Regardless of the restorative material used, the weakest bonds occurred in samples prepared using Maxcem $(\mathrm{P}<0.05)$.

Bonding to $\mathrm{Ni}$-Cr alloy. Multilink Sprint and RelyX Unicem provided similar bond strengths, and performed significantly better than Maxcem ( $\mathrm{P}<0.05$; Fig. 4A).

Bonding to glass-ceramic. The mean bond strengths were relatively low (3.4-10.4 $\mathrm{MPa}$ ). Nevertheless, a significant difference was observed between the cements, with RelyX Unicem (8.2 MPa) being stronger than Multilink Sprint (5.2 MPa), which in turn was stronger than Maxcem (3.4 MPa; $\mathrm{P}<0.05$; Fig. 4B).

Bonding to composite. The highest bond strength occurred in samples prepared using Multilink Sprint (10.5 MPa); however, no significant difference was observed between this value and that of RelyX Unicem (7.7 MPa; Fig. 4C). Maxcem (6.7 MPa) had the lowest bond strength to composite. There was no significant difference between the 3 cements $(P>0.05)$.

Bonding to $Y-T Z P ~ \mathrm{ZrO}_{2}$. RelyX Unicem provided higher mean bond strengths when bonding to Y-TZP $\mathrm{ZrO}_{2}$, however no significant differences were observed when compared with the Multilink Sprint samples (Fig. 4D). RelyX Unicem and Multilink Sprint formed significantly stronger bonds to Y-TZP $\mathrm{ZrO}_{2}$ compared with Maxcem ( $\mathrm{P}<0.05$; Fig. 4D).

\section{Discussion}

Substrate materials used in the present study included $\mathrm{Ni}-\mathrm{Cr}$ alloy, composite, glass-ceramic and Y-TZP $\mathrm{ZrO}_{2}$. The glass-ceramic and Y-TZP $\mathrm{ZrO}_{2}$ surfaces were ground using 800-grit $\mathrm{SiC}$ paper; the $\mathrm{Ni}-\mathrm{Cr}$ alloy and composite surfaces were sandblasted using $50 \mu \mathrm{m}$ alumina $\left(\mathrm{Al}_{2} \mathrm{O}_{3}\right)$. Prior to bonding, the surfaces were thoroughly washed with acetone 
Table III. Results of shear bond strength tests $(n=10)$.

\begin{tabular}{|c|c|c|c|c|c|c|c|c|}
\hline \multirow[b]{2}{*}{ Substrates } & \multicolumn{2}{|c|}{ Ni-Cr alloy } & \multicolumn{2}{|c|}{ Glass-ceramic } & \multicolumn{2}{|c|}{ Composite } & \multicolumn{2}{|c|}{ Y-TZP ZrO } \\
\hline & SBS (MPa) & SD & SBS (MPa) & SD & SBS (MPa) & SD & SBS (MPa) & SD \\
\hline RelyX Unicem & $15.75^{\mathrm{a}}$ & 1.3 & $8.21^{a, b}$ & 1.9 & 7.7 & 2.1 & $21.11^{\mathrm{a}}$ & 6.6 \\
\hline Maxcem & $12.52^{\mathrm{c}}$ & 2.3 & $3.37^{\mathrm{c}}$ & 0.6 & 6.7 & 1.5 & $7.76^{\mathrm{c}}$ & 1.4 \\
\hline Multilink Sprint & 17.63 & 3.5 & 5.23 & 1.1 & 10.5 & 3 & 17.01 & 2.6 \\
\hline
\end{tabular}

Y-TZP, Yttria-tetragonal zirconia polycrystalline ceramic; SBS, shear bond strength; SD, standard deviation. Group with indicators were statistically different from one another $(\mathrm{P}<0.05)$. ${ }^{\mathrm{a}} \mathrm{P}<0.05$ vs. RelyX Unicem, ${ }^{\mathrm{b}} \mathrm{P}<0.05$ vs. Multilink Sprint, ${ }^{\mathrm{c}} \mathrm{P}<0.05$ vs. Multilink Sprint.

A

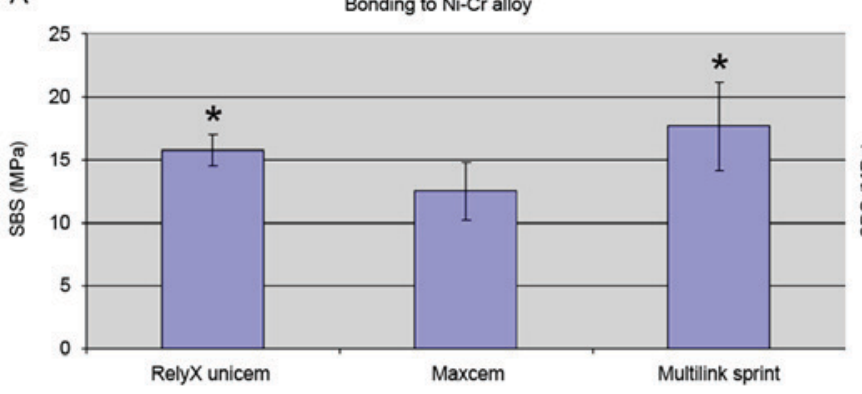

C

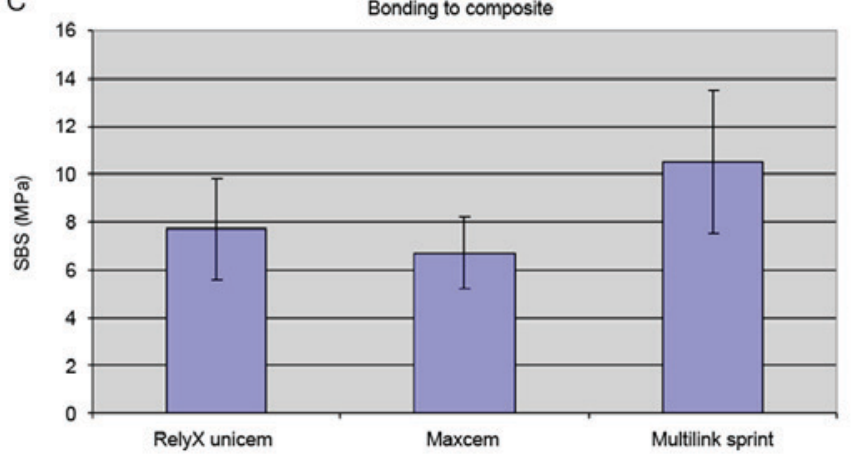

B

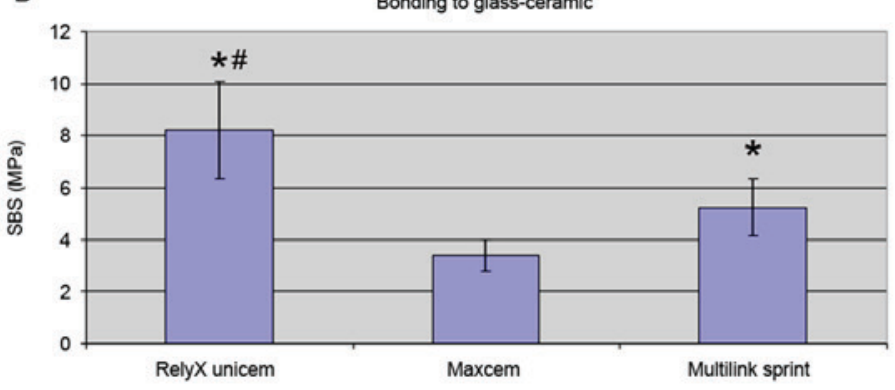

D

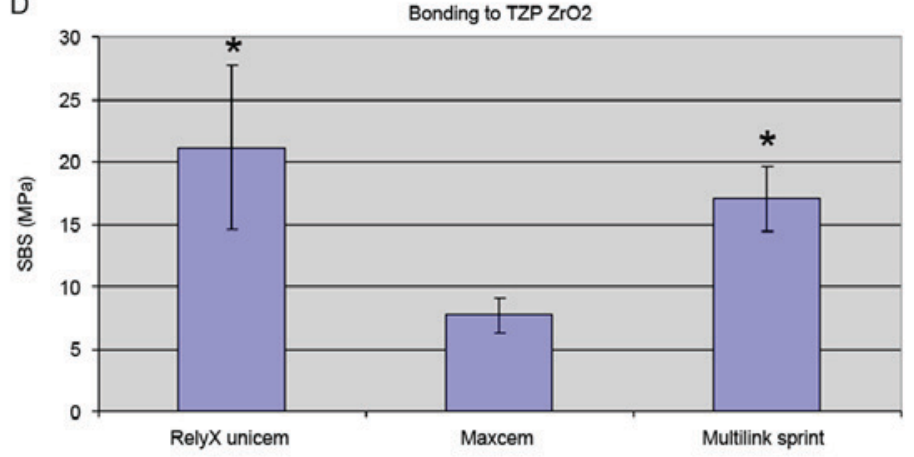

Figure 4. Dentin SBS of RelyX Unicem, Maxcem and Multilink Sprint resin cements bonded to (A) Ni-Cr alloy, (B) glass-ceramic, (C) Composite and (D) Y-TZP ZrO2. Results are presented as the mean \pm standard deviation. $\mathrm{n}=10$. ${ }^{\mathrm{P}}<0.05$ vs. Maxcem and ${ }^{\#} \mathrm{P}<0.05$ vs. Multilink Sprint. SBS, shear bond strength; Y-TZP, Yttria-tetragonal zirconia polycrystalline ceramic.

to eliminate $\mathrm{Al}_{2} \mathrm{O}_{3}$ particles and other residues. Ni-Cr alloy specimens abraded using $50 \mu \mathrm{m} \mathrm{Al} \mathrm{A}_{2} \mathrm{O}_{3}$ particles exhibited higher bond strength to composite resin compared with samples abraded using $250 \mu \mathrm{m}$ particles (13). Based on surface energy and topography measurements of Ni-Cr alloy specimens treated using 4,000 grit $\mathrm{SiC}$ paper, or sandblasted using 50 or $250 \mu \mathrm{m} \mathrm{Al} \mathrm{O}_{3}$, sandblasting increases the polar contributions to surface energy (particularly in the case of $50 \mu \mathrm{m}$ particles) and is able to promote acid-base interactions with adhesives (13).

Debonding at the composite-adhesive interface is a major problem for indirect composite restorations (14). Several studies have indicated that composite surfaces treated by air-abrasion with $\mathrm{Al}_{2} \mathrm{O}_{3}$ exhibit an increase in bond strength between the indirect composite and resin cement $(14,15)$. In particular, air abrasion with $50 \mu \mathrm{m} \mathrm{Al}_{2} \mathrm{O}_{3}$ and tribochemical silica followed by application of the bonding agent has been reported to produce the highest repair shear bond strength (16).
Due to its fracture toughness and chemical durability, Y-TZP $\mathrm{ZrO}_{2}$ is one of the most commonly used all-ceramic core materials (17). Several techniques, including airborne particle abrasion with alumina, have been reported to mechanically enhance the bond strength between resin cement and Y-TZP ceramic (18-20). Other researchers have reported that sandblasting induces transformation of the tetragonal phase to monoclinic, resulting in long-term catastrophic failure (21). The duration of treatment and the particle size used during the abrasion process affect the roughness and phase transformation of Y-TZP; longer treatment times with larger particles may result in material degradation (22).

A recent study indicated that particle abrasion results in matrix erosion and exposure of lithium disilicate crystals in glass ceramic surfaces, whereas hydrofluoric acid etching produced a microroughened surface (23). In the present study, Y-TZP $\mathrm{ZrO}_{2}$ and glass ceramic samples were not sandblasted and were polished using 800-grit SiC instead. 


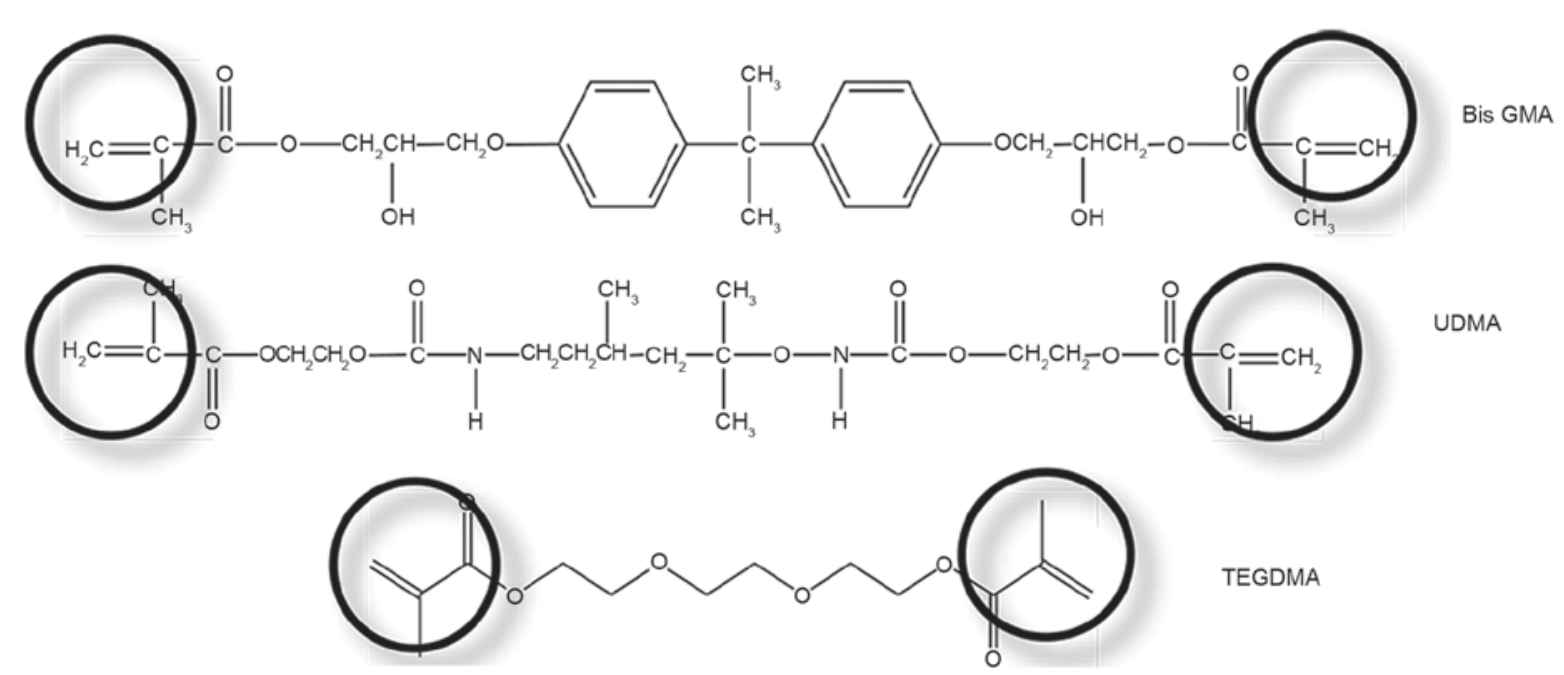

Figure 5. Chemical structures of the methacrylate monomers Bis-GMA, UDMA and TEGDMA. Bis-GMA, 2,2-bis [4-(2-hydroxy-3-methacryloxypropoxy) phenyl]-propane; UDMA, urethane dimethacrylate; TEGDMA, triethyleneglycoldimethacrylate.

All of the self-adhesive resin cements used in the present study contained some type of phosphoric ester-based monomer. Multifunctional phosphoric acid methacrylate monomers incorporate two setting reactions: A polymerizable group that is able to react with other monomers, as well as the restorative material, and an acid adhesive group capable of etching dental hard tissues and interacting with the tooth substance (Fig. 5). In polymer-based self-adhesive resin cements, ionization occurs in situ, utilizing water associated with the dentin or produced during neutralization of the phosphate monomers by basic filler materials (24). Bonding primarily occurs within an interfacial layer incorporating partially dissolved smear particles (25) and possibly involves local formation of a nanohybrid layer (26).

Regardless of the restorative substrate, the weakest bonds observed in the present study were in samples prepared using Maxcem. The principal component of Maxcem is glycerol dimethacrylate dihydrogen phosphate (Fig. 6), a glycerol dimethacrylate ester of phosphoric acid that was one of the first dental materials specifically employed to improve bonding to dentin (27).

The significant differences in bond strength observed between samples prepared using RelyX Unicem and Multilink Sprint, which contain phosphonate groups, and those prepared using Maxcem, which contains phosphate groups, may be attributable to the composition of the adhesive monomer. Bonding occurs between the $\mathrm{Ca}$ ions associated with the hydroxyapatite component of dentin and the ionized phosphoric acid groups of the monomer mixture, creating $\mathrm{Ca}_{3}\left(\mathrm{P}^{5+} \mathrm{O}_{4}\right)_{2}$ in phosphate-based cements and $\mathrm{CaHO}_{3} \mathrm{P}^{3+}$ in phosphonate-based cements.

In the case of acidic methacrylate phosphates, an additional instability results from hydrolysis of the methacrylate ester bond in the presence of water, which is frequently used as a co-solvent in self-etching adhesives (28). Hydrolysis is catalyzed by the hydrogen ions of the phosphoric acid group (29). The phosphoric acid ester bonds in diesters are less hydrolytically stable than monoesters under acidic conditions, including the low pH environment in resin cements (30). Maxcem exhibits a relatively low bonding ability, irrespective of the tooth substrate (31).

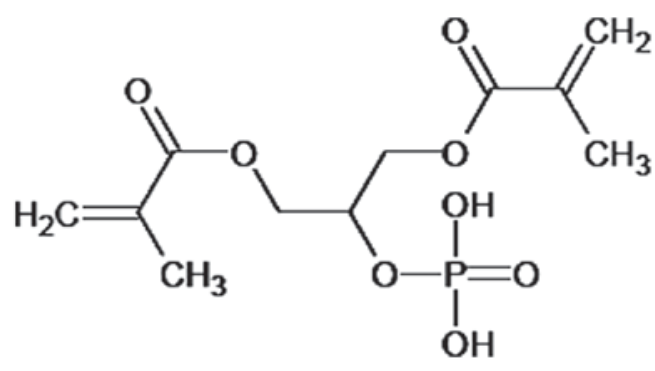

Figure 6. Chemical structures of glycerol dimethacrylate dihydrogen phosphate.

Cross-linking dimethacrylates are used in enamel-dentin adhesives to generate a polymer network, which provides a number of favorable effects. Firstly, the polymerization rate increases due to the gel effect. Secondly, the mechanical properties of a polymer network are improved compared to linear polymers (32). Finally, the cross-linked material is less water soluble and the degree of swelling decreases with increasing polymer network density (33).

A recent study reported that RelyX Unicem is unable to completely dissolve the smear layer. The remaining layer represents a weak zone in the dentin-adhesive interface (7) and explains why the bond strengths achieved using self-adhesive cements are limited regardless of the associated restorative materials. Other researchers have observed that the conventional dual-cured luting cements Multilink Sprint and Multilink Automix provide higher bond strengths compared with self-adhesive resin cements (13).

As resin cements do not contain water, these materials must be applied to slightly wet surfaces for proper adhesion. The $\mathrm{pH}$ values of RelyX Unicem, Maxcem and Multilink Sprintare were $3.78,1.78$ and 3.42 , respectively. Conventional etching-rinse adhesives employ $37 \%$ phosphoric acid, which has a $\mathrm{pH}$ of $\sim 0.7$ (34). The acidity of these self-adhesive resin cements is insufficient to achieve optimal demineralization and infiltration of dentin. As reported by Ferracane et al (10), a hydrophilic character and low $\mathrm{pH}$ in the cured material may compromise mechanical stability by promoting excessive 
water adsorption. Some of the differences observed in the $\mathrm{pH}$ measurements may be a result of the testing method, as the outcome of $\mathrm{pH}$ measurements is dependent on the experimental configuration (2).

In the present study, the surfaces of the zirconia ceramic samples were polished and cleaned prior to bonding. Bonding to flat and smooth surfaces enables a more accurate assessment of the chemical aspects of adhesion. For the bonding of conventional glass ceramics, pretreatment with hydrofluoric acid etching or silanization enhances the resin bond (35). Unlike glass ceramics, zirconia is not susceptible to hydrofluoric acid etching due to its polycrystalline and glass-free nature. However, the phosphoric acid methacrylate monomers of RelyX Unicem have been reported to be particularly effective on zirconia (36). Nevertheless, in the Ni-Cr alloy samples, the phosphonate groups of Multilink Sprint were more effective than the phosphonate groups of RelyX Unicem. Depending on the nature of the multifunctional monomer they contain, self-adhesive resin cements are potentially capable of specific adhesion to selected restorative substrates.

Some limitations of the present study require consideration. Notably, only phosphoric acid derivatives, including phosphonates $\left(\mathrm{H}_{2} \mathrm{PO}_{3}^{+} / \mathrm{HRPO}_{3}{ }^{+}\right)$and phosphates $\left(\mathrm{H}_{2} \mathrm{PO}_{4}^{-} / \mathrm{HRPO}_{4}{ }^{-}\right)$ were studied. Furthermore, some of the differences observed in the $\mathrm{pH}$ measurements may be due to an artifact of the testing method. In future research, more hydrolytically stable esters, including carbamides, could be studied (37), as well as the effectiveness in improving the bond strength by increasing the length of the acidic monomer spacer group.

In conclusion, the performance of an adhesive material depends on the chemical structure of the functional monomer. The $\mathrm{pH}$ of acidic functional monomers containing phosphonate or phosphate groups influences the bond strength between dentin and restorative materials. Further studies are warranted to investigate whether modifying the acidic monomer or changing the monomer spacer length may improve the bond strength.

\section{Acknowledgements}

Not applicable.

\section{Funding}

No funding was received.

\section{Availability of data and materials}

All data generated or analyzed during this study are included in this published article.

\section{Authors' contributions}

WL, ZS and RJ performed the study. HM performed the data analyses. CAD interpreted the data. CZ conceived the study. All authors read and approved the final manuscript.

\section{Ethics approval and consent to participate}

The present study was approved by the Ethics Committee of The First Hospital of Jilin University (Changchun, China) and was performed in accordance with the Declaration of Helsinki of the World Medical Association. All enrolled patients provided written informed consent.

\section{Consent for publication}

Not applicable.

\section{Competing interests}

The authors declare that they have no competing interests.

\section{References}

1. Pameijer CH: A review of luting agents. Int J Dent 2012: 752861, 2012.

2. Zorzin J, Petschelt A, Ebert J and Lohbauer U: pH neutralization and influence on mechanical strength in self-adhesive resin luting agents. Dent Mater 28: 672-679, 2012.

3. Petropoulou A, Vrochari AD, Hellwig E, Stampf S and Polydorou O: Water sorption and water solubility of self-etching and self-adhesive resin cements. J Prosthet Dent 114: 674-679, 2015.

4. Radovic I, Monticelli F, Goracci C, Vulicevic ZR and Ferrari M: Self-adhesive resin cements: A literature review. J Adhes Dent 10: 251-258, 2008.

5. Piwowarczyk A, Bender R, Ottl P and Lauer HC: Long-term bond between dual-polymerizing cementing agents and human hard dental tissue. Dent Mater 23: 211-217, 2007.

6. Ikemura K, Kadoma Y and Endo T: A review of the developments of self-etching primers and adhesives -effects of acidic adhesive monomers and polymerization initiators on bonding to ground, smear layer-covered teeth. Dent Mater J 30: 769-789, 2011.

7. Al-Assaf K, Chakmakchi M, Palaghias G, Karanika-Kouma A and Eliades G: Interfacial characteristics of adhesive luting resins and composites with dentine. Dent Mater 23: 829-839, 2007.

8. Monticelli F, Osorio R, Mazzitelli C, Ferrari M and Toledano M: Limited decalcification/diffusion of self-adhesive cements into dentin. J Dent Res 87: 974-979, 2008.

9. Zorzin J, Petschelt A, Ebert J and Lohbauer U: pH neutralization and influence on mechanical strength in self-adhesive resin luting agents. Dent Mater 28: 672-679, 2012.

10. Ferracane JL, Stansbury JW and Burke FJ: Self-adhesive resin cements - chemistry, properties and clinical considerations. J Oral Rehabil 38: 295-314, 2011.

11. Vrochari AD, Eliades G, Hellwig E and Wrbas KT: Curing efficiency of four self-etching, self-adhesive resin cements. Dent Mater 25: 1104-1108, 2009.

12. Gerth HU, Dammaschke T, Züchner H and Schäfer E: Chemical analysis and bonding reaction of RelyX Unicem and Bifix composites-a comparative study. Dent Mater 22: 934-941, 2006.

13. Zhang $\mathrm{C}$ and Degrange M: Shear bond strengths of self-adhesive luting resins fixing dentine to different restorative materials. J Biomater Sci Polym Ed 21: 593-608, 2010.

14. Kirmali O, Barutcugil C, Harorli O, Kapdan A and Er K: Resin cement to indirect composite resin bonding: Effect of various surface treatments. Scanning 37: 89-94, 2015.

15. Spitznagel FA, Horvath SD, Guess PC and Blatz MB: Resin bond to indirect composite and new ceramic/polymer materials: A review of the literature. J Esthet Restor Dent 26: 382-393, 2014.

16. Cho SD, Rajitrangson P, Matis BA and Platt JA: Effect of Er, Cr:YSGG laser, air abrasion, and silane application on repaired shear bond strength of composites. Oper Dent 38: E1-E9, 2013.

17. Piconi $\mathrm{C}$ and Maccauro G: Zirconia as a ceramic biomaterial. Biomaterials 20: 1-25, 1999.

18. Ozcan M and Vallittu PK: Effect of surface conditioning methods on the bond strength of luting cement to ceramics. Dent Mater 19: 725-731, 2003.

19. Tsukakoshi M, Shinya A, Gomi H, Lassila LV, Vallittu PK and Shinya A: Effects of dental adhesive cement and surface treatment on bond strength and leakage of zirconium oxide ceramics. Dent Mater J 27: 159-171, 2008.

20. Blatz MB, Chiche G, Holst S and Sadan A: Influence of surface treatment and simulated aging on bond strengths of luting agents to zirconia. Quintessence Int 38: 745-753, 2007. 
21. Denry IL and Holloway JA: Microstructural and crystallographic surface changes after grinding zirconia-based dental ceramics. J Biomed Mater Res B Appl Biomater 76: 440-448, 2006.

22. Turp V, Sen D, Tuncelli B, Goller G and Özcan M: Evaluation of air-particle abrasion of Y-TZP with different particles using microstructural analysis. Aust Dent J 58: 183-191, 2013.

23. Aboushelib MN and Sleem D: Microtensile bond strength of lithium disilicate ceramics to resin adhesives. J Adhes Dent 16: 547-552, 2014

24. Catel Y, Besse V, Zulauf A, Marchatc D, Pfunda E, Phama TN Bernache-Assolantc D, Degrangeb M, Lequeuxa T, Madeca PJ and Pluart LL: Synthesis and evaluation of new phosphonic, bisphosphonic and difluoromethylphosphonic acid monomers for dental application. Eur Polym J 48: 318-330, 2012.

25. Pedreira AP, Pegoraro LF, de Góes MF, Pegoraro TA and Carvalho RM: Microhardness of resin cements in the intraradicular environment: Effects of water storage and softening treament. Dent Mater 25: 868-876, 2009.

26. Van Landuyt KL, Snauwaert J, De Munck J, Peumans M Yoshida Y, Poitevin A, Coutinho E, Suzuki K, Lambrechts P and Van Meerbeek B: Systematic review of the chemical composition of contemporary dental adhesives. Biomaterials 28: 3757-3785, 2007.

27. Stona P, Borges GA, Montes MA, Júnior LH, Weber JB and Spohr AM: Effect of polyacrylic acid on the interface and bond strength of self-adhesive resin cements to dentin. J Adhes Dent 15: 221-227, 2013.

28. Yoshihara K, Nagaoka N, Okihara T, Kuroboshi M, Hayakawa S, Maruo Y, Nishigawa G, De Munck J, Yoshida Y and Van Meerbeek B: Functional monomer impurity affects adhesive performance. Dent Mater 31: 1493-1501, 2015.

29. Moszner N, Zeuner F, Angermann J, Fischer UK and Rheinberger V: Monomers for adhesive polymers, 4. Macromol Mater Eng 288: 621-628, 2003
30. Cal E, Türkün LS, Türkün $M$, Toman $M$ and Toksavul S: Effect of an antibacterial adhesive on the bond strength of three different luting resin composites. J Dent 34: 372-380, 2006.

31. Goracci C, Cury AH, Cantoro A, Papacchini F, Tay FR and Ferrari M: Microtensile bond strength and interfacial properties of self-etching and self-adhesive resin cements used to lute composite onlays under different seating forces. J Adhes Dent 8: 327-335, 2006.

32. Yamasaki LC, De Vito Moraes AG, Barros M, Lewis S, Francci C, Stansbury JW and Pfeifer CS: Polymerization development of 'low-shrink' resin composites: Reaction kinetics, polymerization stress and quality of network. Dent Mater 29: e169-e179, 2013.

33. Moszner N, Salz U and Zimmermann J: Chemical aspects of self-etching enamel-dentin adhesives: A systematic review. Dent Mater 21: 895-910, 2005.

34. Peumans M, De Munck J, Mine A and Van Meerbeek B: Clinical effectiveness of contemporary adhesives for the restoration of non-carious cervical lesions. A systematic review. Dent Mater 30: 1089-1103, 2014

35. Oyagüe RC, Monticelli F, Toledano M, Osorio E, Ferrari M and Osorio R: Effect of water aging on microtensile bond strength of dual-cured resin cements to pre-treated sintered zirconium-oxide ceramics. Dent Mater 25: 392-399, 2009.

36. Kilambi H, Beckel ER, Berchtold KA, Stansbury JW and Bowman CN: Influence of molecular dipole on monoacrylate monomer reactivity. Polymer 46: 4735-4742, 2005.

37. Cakir FY, Korkmaz Y, Firat E, Oztas SS and Gurgan S: Chemical analysis of enamel and dentin following the application of three different at-home bleaching systems. Oper Dent 36: 529-536, 2011. 